

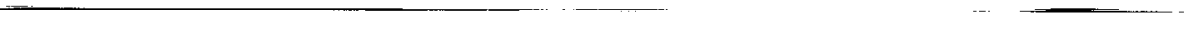
$=$ .

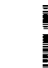




\title{
AN ENTRY FLIGHT CONTROLS ANALYSIS FOR A REUSABLE LAUNCH VEHICLE
}

\author{
Philip Calhoun \\ NASA Langley Research Center \\ Hampton, VA 23681
}

\begin{abstract}
The NASA Langley Research Center has been performing studies to address the feasibility of various single-stage to orbit concepts for use by NASA and the commercial launch industry to provide a lower cost access to space. Some work on the conceptual design of a typical lifting body concept vehicle, designated VentureStar ${ }^{\mathrm{TM}}$ has been conducted in cooperation with the Lockheed Martin Skunk Works. This paper will address the results of a preliminary flight controls assessment of this vehicle concept during the atmospheric entry phase of flight. The work includes control analysis from hypersonic flight at the atmospheric entry through supersonic speeds to final approach and landing at subsonic conditions. The requirements of the flight control effectors are determined over the full range of entry vehicle Mach number conditions. The analysis was performed for a typical maximum crossrange entry trajectory utilizing angle of attack to limit entry heating and providing for energy management, and bank angle to modulation of the lift vector to provide downrange and crossrange capability to fly the vehicle to a specified landing site. Sensitivity of the vehicle open and closed loop characteristics to CG location, control surface mixing strategy and wind gusts are included in the results. An alternative control surface mixing strategy utilizing a reverse aileron technique demonstrated a significant reduction in RCS torque and fuel required to perform bank maneuvers during entry. The results of the control analysis revealed challenges for an early vehicle configuration in the areas of hypersonic pitch trim and subsonic longitudinal controllability.
\end{abstract}

\section{NOMENCLATURE}

$\mathrm{C}_{1} \quad$ rolling moment aerodynamic coefficient $\mathrm{C}_{\mathrm{m}} \quad$ pitching moment aerodynamic coefficient $\mathrm{C}_{\mathrm{n}} \quad$ yawing moment aerodynamic coefficient

'Research Engineer, Vehicle Analysis Branch, Aerospace Systems Concepts and Analysis Competency,

Copyright (1) 2000 American Institute of Aeronautics and Astronautics, Inc. No copyright is asserted in the United States under Title 17, U.S. Code. The U.S. Government has a royaltyfree license to exercise all rights under the copyright claimed herein for Governmental purposes. All other rights are reserved by the copyright owner.

$\begin{array}{ll}C_{l_{\beta}} & \delta C_{1} / \delta \beta, \text { deg }^{-1} \\ C_{m_{\alpha}} & \delta C_{m} / \delta \alpha, \text { deg }^{-1} \\ C_{n} & \delta C_{n} / \delta \beta, \text { deg }^{-1} \\ C G & \text { Center of Gravity } \\ \text { DOF } & \text { Degrees of Freedom } \\ \text { LaRC } & \text { Langley Research Center } \\ \text { LCDP } & \text { Lateral Control Departure Parameter } \\ \text { LMSW } & \text { Lockheed Martin Skunk Works } \\ \text { LOX } & \text { Liquid Oxygen } \\ \text { RCS } & \text { Reaction Control System } \\ \text { TAEM } & \text { Terminal Area Energy Management } \\ \alpha & \text { Angle of Attack, deg } \\ \beta & \text { Sideslip Angle, deg }\end{array}$

\section{INTRODUCTION}

The NASA Langley Research Center, in cooperation with Lockheed Martin Skunk Works (LMSW), participated in a conceptual design study for a single stageto- orbit reusable vehicle.' This reusable vehicle concept, proposed by LMSW, is a lifting body configuration called the VentureStar ${ }^{\mathrm{TM}}$. This paper documents a flight controls analysis performed at LaRC to address the flyability of an early VentureStar ${ }^{\mathrm{TM}}$ configuration similar to the $\mathrm{X}-33$ configuration. The VentureStar ${ }^{\mathrm{TM}}$ concept vehicle had undergone several design and configuration changes during early conceptual studies. Figure 1 shows a typical early VentureStar ${ }^{\mathrm{TM}}$ vehicle configuration similar to the one that will be addressed in this paper. The control

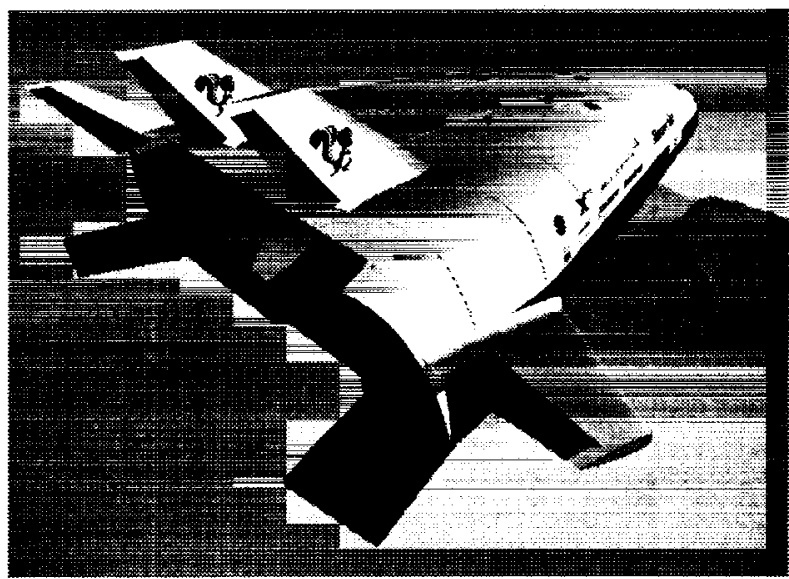

Figure 1. Typical Early VentureStar ${ }^{T M}$ Configuration.

1

American Institute of Aeronautics and Astronautics 
surfaces, evident from the configuration aft view, include body flaps at the outboard engine locations, inboard and outboard elevons on the canted fins, and two rudders on the vertical tails. This configuration is similar to the one analyzed in this controls analysis with the exception of the replacement of twin vertical tails with a single vertical tail and rudder for yaw control. A combination of these aero surfaces and RCS jets was utilized to control and stabilize the vehicle during entry and landing phases of flight. The RCS jets used for entry control are located on the aft outboard surfaces and oriented to fire vertically for pitch and roll and aft and outboard for yaw control.

\section{ENTRY FLIGHT CONTROL OVERVIEW}

During the hypersonic entry phase, the guidance system will command the vehicle to maintain the angle of attack to limit the maximum heat rate. ${ }^{2}$ During the entry phase, bank reversals of up to \pm 90 deg are commanded to adjust the nominal trajectory downrange and crossrange. Bank reversals and angle of attack maneuvers, below about Mach 15, are used to adjust the vehicle trajectory as required to meet specific flight conditions at the Terminal Area Energy Management (TAEM) interface at about Mach 2.5. The vehicle is commanded to follow a heading alignment cylinder and maintain flight path angle commands to control the trajectory from the TAEM interface to approach and landing. Flight conditions for a typical entry were provided by a LaRC flight mechanics team, using the Program to Optimize Simulated Trajectories (POST) trajectory analysis tool. ${ }^{3}$ Nominal values of angle of attack, bank angle and dynamic pressure variations with Mach number during the entry and landing phases are shown in Figure 2. They represent typical values for an 800 mile maximum crossrange trajectory.
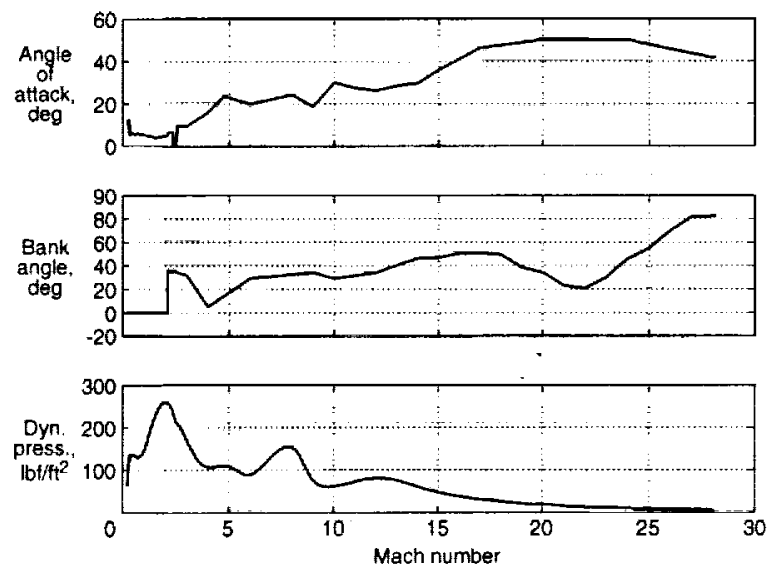

Figure 2. Maximum Crossrange Trajectory.
An analysis of the entry and landing phases was completed to assess the configuration design flyability and requirements for the RCS and control surface rates and deflections. An aerodynamics database, representative of the early VentureStar ${ }^{\mathrm{TM}}$ configuration, was provided by LMSW for stability and controls analysis. The database includes longitudinal and lateral/directional force and moment coefficients for typical flight conditions over the entire Mach range. Data was provided at a moment reference center along the vehicle centerline at 66.0 percent of the vehicle reference length. Aerodynamic control surface deflection requirements for pitch trim were determined for the maximum crossrange trajectory. The surface deflection requirements for trim for this trajectory are shown in Figure 3. This plot represents equal angle deflections of the body flaps, inboard and outboard elevons required to provide pitch trim along the trajectory from entry to landing. For this analysis, the body flaps and elevons deflect equally. The figure shows the required deflections with the data adjusted to CG locations at several positions. A CG of $71.8 \%$ of the reference length is the aft most location that allows pitch trim to be possible given the assumed maximum control surface deflections of $\pm 30 \mathrm{deg}$ for the elevons and +30 , $-15 \mathrm{deg}$ for the body flaps. However, typical thermal heat loads on the control surfaces limit the sustained surface deflections to +15 deg during hypersonic flight. In addition, the control deflections for trim are typically limited to $\pm 15 \mathrm{deg}$ to maintain vehicle controllability over all flight conditions without excessive use of RCS. This is particularly true if the vehicle is either neutrally stable or marginally unstable in either the Iongitudinal or lateral directional modes. The CG should be no further aft than $70.3 \%$ of the body reference length to meet these trim constraints for the trajectory flight conditions shown in Figure 2. The trim deflections are also shown for a CG location of $67.3 \%$ representing the sensitivity

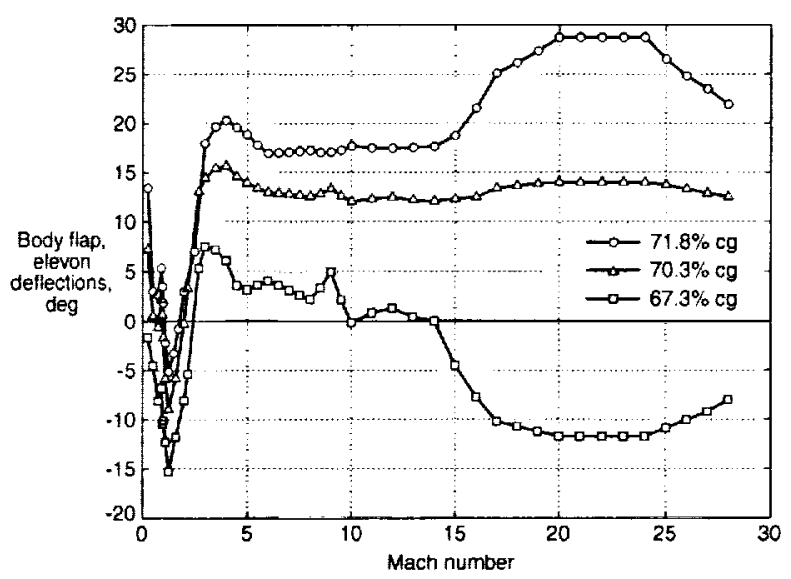

Figure 3. Body Flap, Elevon Deflections for Trim. 
to a forward CG shift such as would occur with the payload returned in an extreme forward payload bay location. The hypersonic pitch trim issue was a challenge for this configuration. For the purposes of this study, it was assumed that as the design matured the combination of CG location, aerodynamic moment center, and control surface effectiveness will allow pitch trim of the vehicle within the feasible range of control surface deflections.

\section{VEHICLE OPEN LOOP CHARACTERISTICS}

Consideration of the vehicle open loop stability characteristics provides some insight into vehicle controllability prior to the design of a closed loop system. Stability derivatives and indicators are shown in Figures 4-6 for both the aft $(70.3 \%)$ and forward $(67.3 \%)$ CG locations. Figure 4 shows plots of the aerodynamic stability derivatives providing an indication of the static stability of the vehicle. The values were computed at the trim conditions for selected points along the nominal maximum crossrange trajectory shown in Figures 2 and 3. The derivative of pitching moment coefficient with respect to angle of attack $\left(\mathrm{C}_{\mathrm{m}_{\mathrm{o}}}\right)$ shows the longitudinal pitch axis mode is slightly unstable above Mach 15 and slightly stable down to Mach 4 for the aft CG location of $70.3 \%$. The vehicle becomes increasingly unstable below Mach 3 particularly at subsonic conditions near landing. The static margin, depicting the location of the vehicle CG relative to the neutral point is shown in Figure 5 and is considered a good indicator of pitch axis stability. The static margin for the aft CG location remains relatively small for flight conditions above Mach 1.2. Below Mach 1.2 the static margin decreases and the vehicle becomes more unstable, especially as the angle of attack increases at low subsonic landing conditions. Figure 5 shows effect on the doubling time for the short period mode for
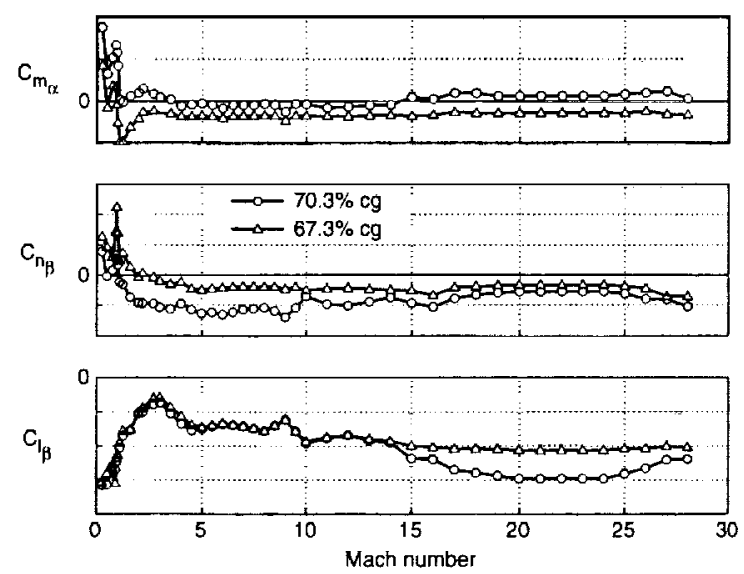

Figure 4. Stability Derivatives.
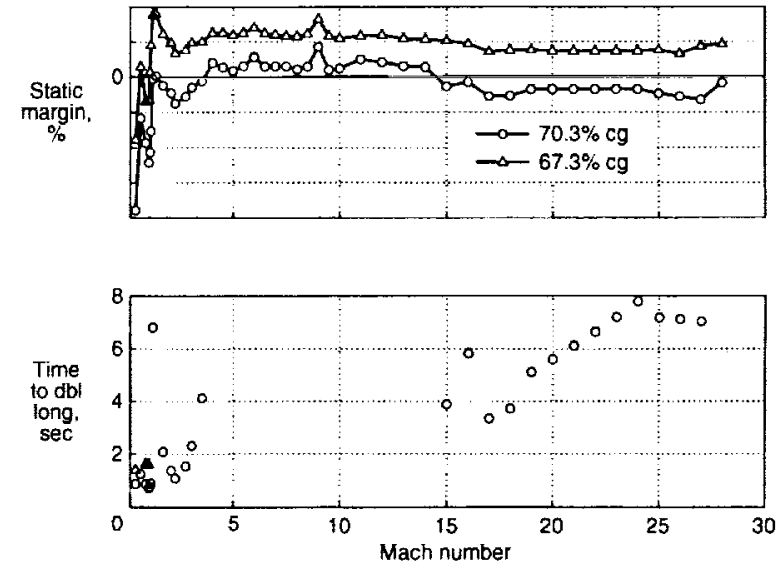

Figure 5. Longitudinal Stability Indicators.

the unstable flight conditions. The relatively large time to double above Mach 3 indicates that closed loop stability augmentation can be accomplished with moderate demands on control surface rates and deflections during hypersonic and high supersonic flight. Below Mach 3 the doubling time becomes shorter reaching a minimum. during subsonic flight conditions. This indicates moderately unstable subsonic flight conditions for the aft CG location and will require relatively large control surface rates and deflections to stabilize the vehicle pitch dynamics. The situation improves somewhat at the forward CG location where the vehicle has good pitch stability over most conditions above transonic speeds. Subsonic flight is still pitch unstable with relatively low doubling time.

The open loop lateral/directional stability characteristics can be approximately determined from the stability derivatives and indicators shown in Figures 4 and 6 . The derivative of yaw moment coefficient with re-
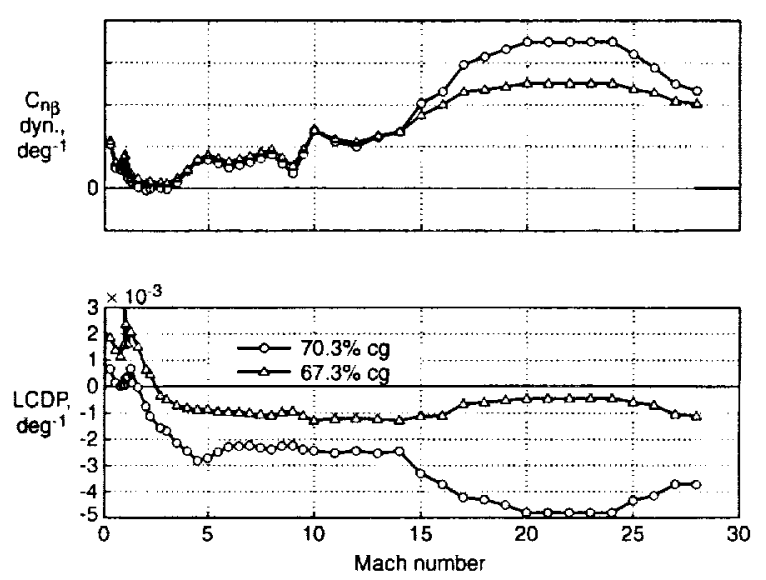

Figure 6. Lateral/Directional Stability Indicators. 
spect to sideslip $\left(\mathrm{C}_{\mathrm{n}_{\beta}}\right)$, referred to as yaw stiffness, has a negative value throughout the trajectory down to Mach 1.2 for the aft CG location. This indicates the potential for directional instability in the transonic, supersonic and hypersonic regimes. The lateral stability is indicated by the derivative of roll moment coefficient with respect to sideslip $\left(C_{10}\right)$, referred to as the effective dihedral. The effective dihedral is negative over the entire trajectory indicating static roll stability. Since the directional and lateral motions of the vehicle are coupled, only a dynamic analysis can be used to determine the actual stability characteristics. However, other parameters, which use these static stability derivatives, have been shown to be good indicators of the lateral/directional departure and spin susceptibility characteristics of aircraft. ${ }^{+}$The discussion in this reference utilizes a combined directional stability parameter called $C_{n_{\beta}}$ dynamic $\left(C_{n_{\beta}}\right.$, dyn) and the lateral control departure parameter (LCDP) for characterizing the open loop lateral/directional stability. Plots of these parameters over the trajectory flight conditions are shown in Figure 6.

$\mathrm{C}_{\mathrm{n},}$, dynamic is defined as,

$C_{n_{\beta, d y n}}=C_{n_{\beta}} \cos (\alpha)-\frac{I_{z z}}{I_{x x}} C_{l_{\beta}} \sin (\alpha)$

and LCDP defined as,

$L C D P=C_{n_{\beta}}-\frac{C_{n_{\delta a}}}{C_{l_{\delta a}}} C_{l_{\beta}}$

Positive values of both $C_{n_{\beta}}$ dynamic and LCDP indicale no susceptibility to spin departure. During the high angle of attack, hypersonic phase of flight $C_{n_{\beta}}$, dyn. is positive, but LCDP is negative. $C_{n_{\beta}}$ is small relative to $C_{1_{\beta}}$ which when combined with the ratio of yaw to roll incrtia produces a positive value of $\mathrm{C}_{\mathrm{n}_{\beta}}$, dyn. The value becomes smaller as the angle of attack is lowered and the dihedral effect becomes less negative. The LCDP parameter remains negative down to transonic speeds due to the adverse yaw produced by the ailerons. The LCDP parameter indicates an improvement in spin departure susceptability as the vehicle CG is shifted to the forward location. There is little change in $C_{n_{\beta}}$, dyn expected during the high angle of attack flight where the dihedral effect dominates and $C_{n_{\beta}}$, dyn. becomes less positive as the CG moves forward. The spin susceptibility has been categorized into none, mild, moderate or severe regions based on the values of these stability indicators. ${ }^{4}$ Positive values of LCDP indicate no spin departure tendency while moderately negative values, especially when combined with a value of negative Cnb, dyn., indicate moderate or severe susceptibility. Mild departure tendencies are indicated by positive $C_{n_{\beta}}$, dyn and a negative LCDP value. These criteria demonstrated good correlation when compared to the spin characteristics witnessed from wind tunnel and fight tests for several operational vehicles. ${ }^{4}$ Using the criteria discussed in this reference, the configuration with the aft CG location remains in the mild departure susceptibility region down to around Mach 3 where near zero values of $C_{n_{\beta}}$, dyn and negative LCDP move it close to the moderate departure susceptibility region. The situation improves with the forward CG location where there is either mild or no susceptibility to spin departure throughout the entire trajectory.

In summary, the open loop analysis shows regions of concern for the vehicle stability, especially in the longitudinal dynamics, over transonic and subsonic flight conditions. The situation improves for the forward vehicle $C G$ locations but stability concerns still remain in the subsonic flight regime.

\section{CONTROL ANALYSIS METHODOLOGY}

The flight controls study included the design of candidate control laws and analysis utilizing a non-linear six-degree of freedom (6DOF) simulation of closed loop flight conditions. The results include estimates of RCS moment and aero surface deflections and rates required to perform required guidance maneuvers in the presence of wind turbulence. Angle of attack, sideslip and bank angle response to maneuver commands were also included in the results. First, a set of linearized dynamic equations of motion were derived at selected flight conditions along the trajectory from entry to landing for the purpose of control law design. The resulting controller design was included in a nonlinear 6DOF simulation to study the robustness of the closed loop design using wind gusts applied during guidance maneuvers. Control gains for flight conditions between design points were determined using linear interpolation. Angle of attack and bank angle doublet maneuvers were used to exercise the vehicle rate and acceleration conditions required by the guidance system. The vehicle rate and acceleration requirements used for this study are shown in Table 1 for the various flight phases and conditions. The

Table I. Nominal Maneuver Requirements

\begin{tabular}{ccccc}
\hline \hline Mach & $\begin{array}{c}\text { Pitch } \\
\text { Rate }\end{array}$ & $\begin{array}{c}\text { Pitch } \\
\text { Accel. }\end{array}$ & $\begin{array}{c}\text { Bank } \\
\text { Rate }\end{array}$ & $\begin{array}{c}\text { Bank } \\
\text { Accel. }\end{array}$ \\
\hline $25-20$ & $2 \mathrm{deg} / \mathrm{s}$ & $1 \mathrm{deg} / \mathrm{s}^{2}$ & $5 \mathrm{deg} / \mathrm{s}$ & $1 \mathrm{deg} / \mathrm{s}^{2}$ \\
$20-8$ & $2-4 \mathrm{deg} / \mathrm{s}$ & $1-2 \mathrm{deg} / \mathrm{s}^{2}$ & $5 \mathrm{deg} / \mathrm{s}$ & $1-2 \mathrm{deg} / \mathrm{s}^{2}$ \\
$8-2$ & $4 \mathrm{deg} / \mathrm{s}$ & $2 \mathrm{deg} / \mathrm{s}^{2}$ & $5 \mathrm{deg} / \mathrm{s}$ & $2 \mathrm{deg} / \mathrm{s}^{2}$ \\
\hline \hline
\end{tabular}


values represent typical guidance maneuver requirements for entry vehicles. The inertia properties and the RCS location information used in this study were approximate values representative of the VentureStar ${ }^{\mathrm{TM}}$ configuration shown in Figure 1.

Linearized models of the lateral and longitudinal dynamics for selected points along the nominal trajectory from entry at Mach 25 to landing at subsonic speeds were developed for control law design. The control gains were determined using a Linear Quadratic Regulator (LQR) modern control design approach. The LQR design uses full state feedback and is applied to the lateral/ directional states separately from the longitudinal states. The states used in the design are angle of attack, pitch angle, pitch rate, integral of angle of attack, sideslip angle, roll angle, yaw rate, roll rate, integral of sideslip angle and integral of roll angle. The LQR performance index weighting matrices are tuned to provide the desired vehicle response while simultaneously minimizing the control effector requirements. These gains are determined by tuning the control response in separate linear simulations of the lateral/directional and longitudinal dynamics. This technique provides an effective method to design and analyze the closed loop vehicle responses over the entire trajectory. The approach was to design the control system to use the available aerodynamic surface control effectiveness before resorting to the RCS. The RCS fuel estimates may be used for comparative purposes to evaluate the capability and efficiency of candidate control surface mixing strategies. This approach has been automated using the Matlab software controls functions 5 allowing rapid control design for a large number of trajectory points.

A nonlinear 6-DOF simulation, constructed using the Matlab ${ }^{6}$ and Simulink ${ }^{7}$ software tools, was used to evaluate the design and determine the required control effector requirements. The model includes non-linear rigid body dynamics, 6 DOF aero, Dryden wind gust model and linear actuator response models with command rate limiting. The Dryden gust model is a wind turbulence model recommended for study of vehicle response to winds for horizontally flying vehicles. ${ }^{8} \mathrm{~A}$ brief description of the model is given in the wind gust section at the end of the paper. The 1976 US Standard atmosphere was used to generate the atmospheric density and speed of sound along the trajectory. This simulation provided an independent evaluation of the linearized model assumptions and demonstration of the control design performance and robustness.

\section{ENTRY TO TAEM ANALYSIS}

The control laws were designed at 30 selected flight conditions along the entire trajectory from Mach 25 to the TAEM at about Mach 2.5. The flight control over this region was designed to provide a required vehicle response to typical bank and angle of attack doublet commands. Table 1 shows the magnitude of rates and accelerations of the doublet maneuvers used in the design process over the Mach number range from entry to TAEM. The entry flight control design uses a set of elevons, body flaps, and 3-axis RCS for control effectors during the entry phase. The control design utilizes both elevons and body flaps for trim and pitch control throughout entry, decent, and landing. Since the different roll/ yaw effectiveness ratio of the body flaps and elevons provide a mechanism for independent roll and yaw control, the RCS is augmented with elevons and body flaps for roll/yaw control above Mach 2.5. Below Mach 2.5 the rudder becomes effective and is used for yaw control and roll control is provided primarily by the elevons with some assistance from the body flaps. The elevons and the rudder were limited to about \pm 30 deg deflections and 30 $\mathrm{deg} / \mathrm{sec}$ rates. The body flaps were limited to $+.30 \mathrm{deg}$ and $-15 \mathrm{deg}$ deflection and $20 \mathrm{deg} / \mathrm{sec}$ rates. The feedback control laws were incorporated into the $6 \mathrm{DOF}$ simulation with linear actuator models. Control surface actuators were modeled with a 2 nd order, linear dynamic characteristic with a $4 \mathrm{hz}$ bandwidth. Rate and deflection limits were imposed on the control surface commands.

Several control surface mixing strategies were investigated before settling on a nominal design. The selected nominal design used the body flaps and elevons with a ratio of 3:1 body flap to elevon deflections for the pitch control. Body flaps and elevons were commanded independently utililizing the remaining control surface effectiveness for roll/yaw control. This approach was chosen since the body flaps had significantly more pitch effectiveness and only slightly more roll/yaw effectiveness than the elevons. Closed loop vehicle dynamic response to typical angle of attack and bank angle guidance doublet commands for representative flight conditions at Mach 20 and 8 are shown in Figures 7-14. For the purposes of evaluating the vehicle maneuverability the wind turbulence model was not included in these doublet responses. The plots show vehicle response, control surface deflections and rates, and RCS torque and estimated fuel usage from the 6 DOF simulation. The bank and angle of attack maneuvers are performed so that the maximum rates and accelerations in each axis occur simultaneously. The resulting control surface and RCS responses represent the total amount needed to perform these maneuvers at the required rates and accelerations. 


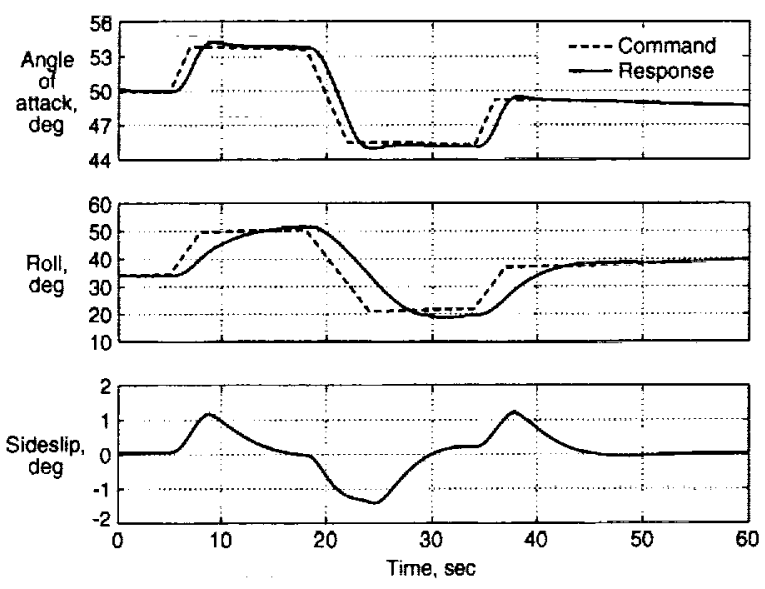

Figure 7. Mach 20 Guidance Doublet Maneuvers. (CG location $=70.3 \%)$
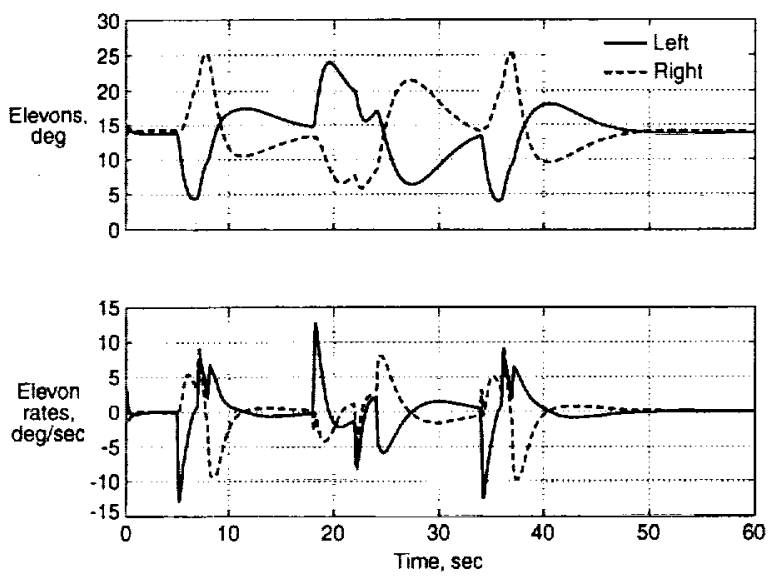

Figure 8. Mach 20 Guidance Doublet Maneuvers. (CG location $=70.3 \%)$
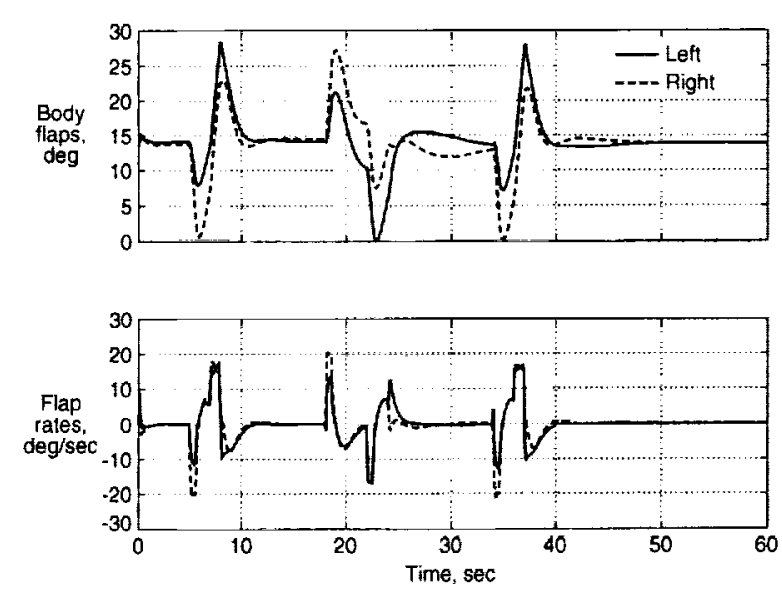

Figure 9. Mach 20 Guidance Doublet Maneuvers. $(C G$ location $=70.3 \%)$
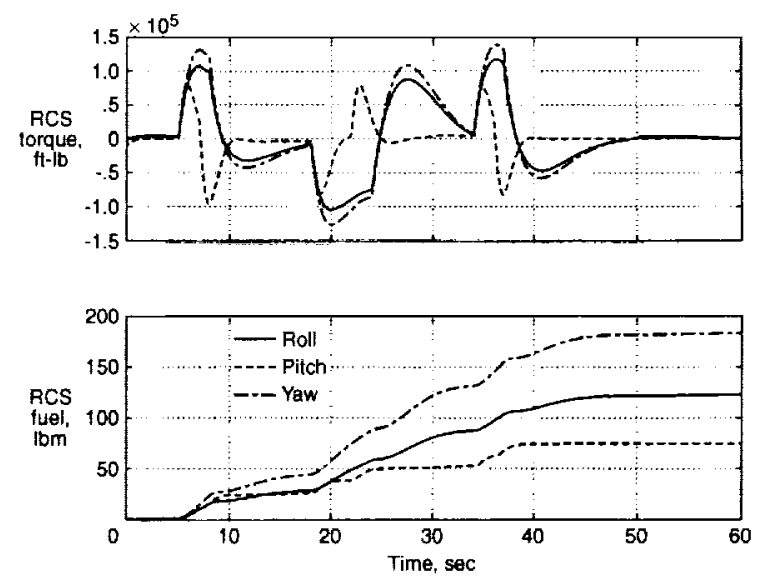

Figure 10. Mach 20 Guidance Doublet Maneuvers. (CG location $=70.3 \%$ )
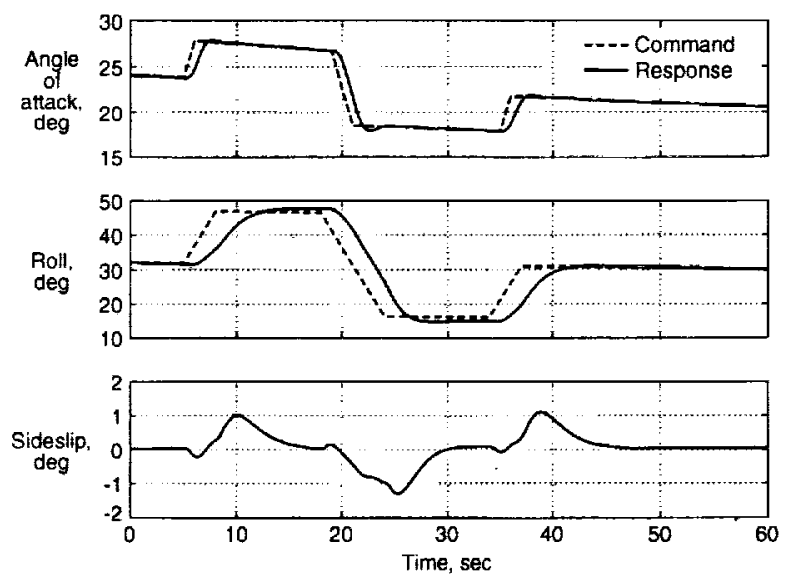

Figure 11. Mach 8 Guidance Maneuvers. (CG location $=70.3 \%)$
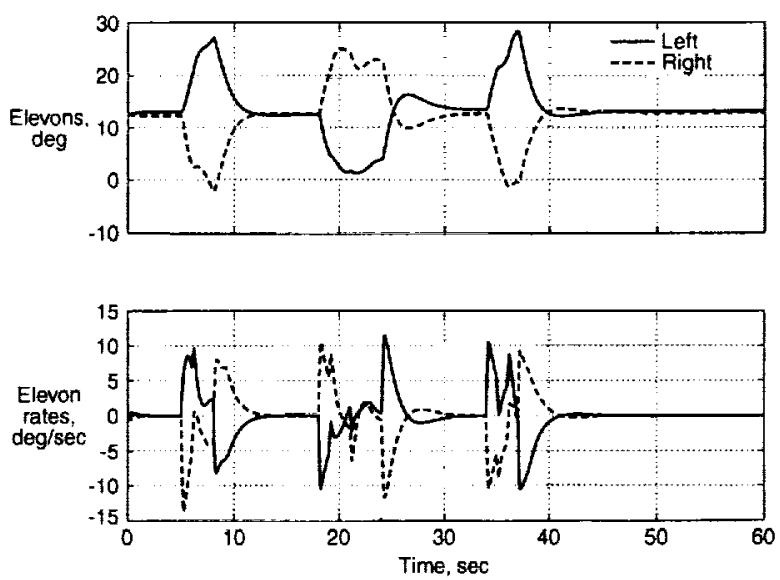

Figure 12. Mach 8 Guidance Maneuvers. (CG location $=70.3 \%$ ) 

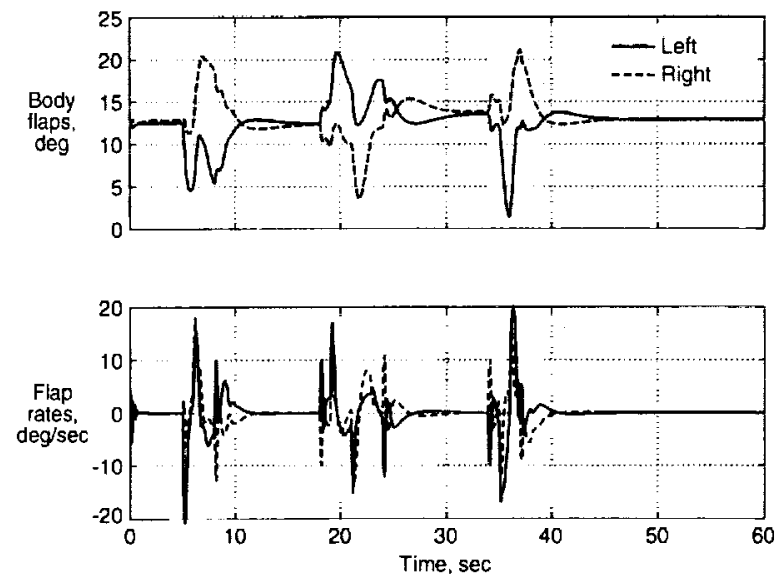

Figure 13. Mach 8 Guidance Maneuvers. $(C G$ location $=70.3 \%)$
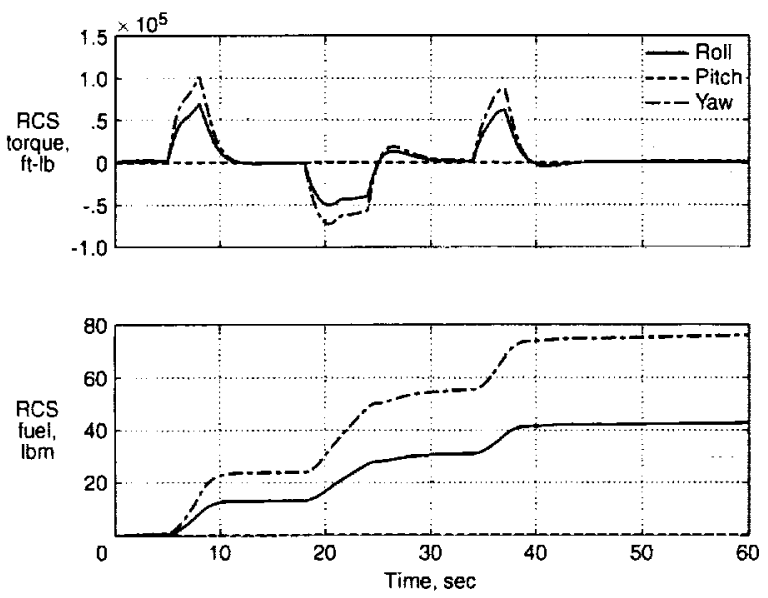

Figure 14. Mach 8 Guidance Maneuvers. $(C G$ location $=70.3 \%)$

The estimate of RCS fuel usage is computed by integration of the required RCS force and not the result of a complete RCS jet model. A constant specific impulse of $400 \mathrm{sec}$ was used to represent a value theoretically achievable for LOX/Hydrogen reaction jets at near vacuum conditions. The resulting fuel values would have to be scaled to account for different ISP values resulting from atmospheric pressure losses and different fuel/oxidizer combinations. The estimates included in this paper were considered to be informative for relative comparison purposes. Actual vehicle fuel budget calculations would require more accurate RCS modeling.

Figures 7 and 11 show angle of attack and roll guidance commands and vehicle response for the Mach 20 and 8 respectively. The guidance commands are shown in dashed lines and the responses in the solid lines. The angle of attack and roll responses for both flight condi- tions meet the required maneuver rates and demonstrate excellent response to simultaneous pitch and roll doublet commands. The angle of attack response is well damped with small overshoot and steady state error. Good bank turn coordination is accomplished with the induced vehicle sideslip remaining less than $1.5 \mathrm{deg}$ throughout the bank maneuver.

Figures 8 and 12 show the left (solid) and right (dashed) elevon deflections and rates required to perform the maneuvers. The elevon deflections nearly reach their design constraints of $30 \mathrm{deg}$. with some allowance left over for response to wind turbulence. The elevons are commanded asymmetrically providing mostly roll/yaw effectiveness. The body flap deflections are shown in Figures 9 and 13. The flap deflections are pushed to near their maximum positive values during the maneuvers for the Mach 20 condition. The RCS torque required to complete the maneuver is shown in Figure 10 along with an estimate of fuel usage. Low dynamic pressure during this phase limits the ability of the control surfaces to accomplish the design maneuver without significant RCS torque. The required RCS torque in all three axis may produce excessive requirements on RCS jets for the hypersonic flight conditions. Guidance strategy may have to be designed to perform required bank maneuvers at higher dynamic pressures near conditions less than Mach 10 - 15 where the required RCS torque is at a reduced level. The pitch axis RCS torque requirements, shown in Figure 14, are reduced to negligible levels by Mach 8 conditions since the control surfaces are adequate to provide pitch maneuverability. However, the roll and yaw torques are still substantial, particularly the yaw torque. Further work to tune the control mixing strategy, utilizing the additional available body flap deflections at Mach 8 may reduce the required roll and yaw RCS torque.

A control strategy known as the reverse aileron technique was studied as an alternative that could reduce the RCS torque and fuel consumption requirements. This method commands the aileron in a reverse direction rolling the vehicle a small amount in the direction opposite the intended bank maneuver. This induces a small sideslip angle which allows the large negative dihedral effect to roll the vehicle back toward the direction of the maneuver. The sideslip is reduced to zero as the vehicle roll reaches the commanded maneuver rate. The advantageous use of the aerodynamic effects of sideslip angle reduces the roll and yaw control authority needed to complete the maneuver. Figure 15 shows the guidance maneuver response utilizing this technique. The roll response is initiated with a 2 deg roll opposite the commanded maneuver direction which induces about a $\mathrm{I}$ deg sideslip. This is apparent in the response, particu- 

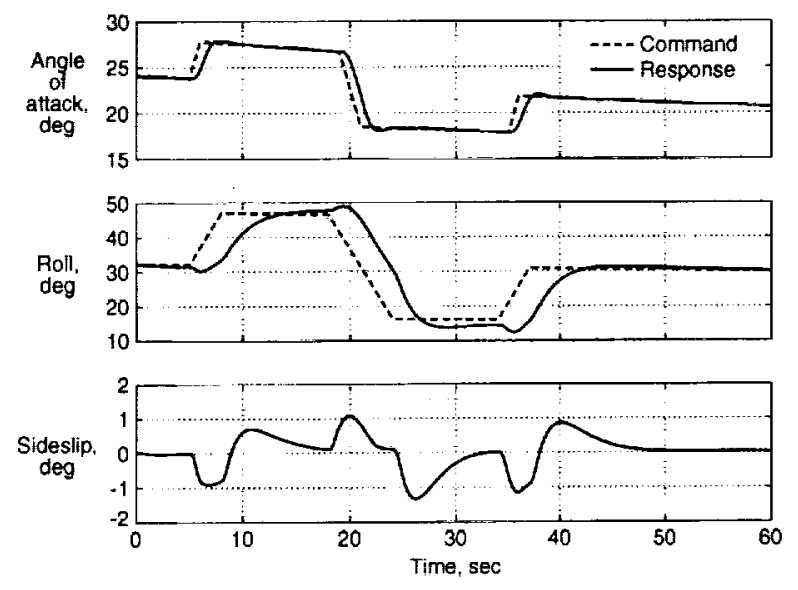

Figure 15. Mach 8 Reverse Aileron Maneuvers. $(C G$ location $=70.3 \%)$
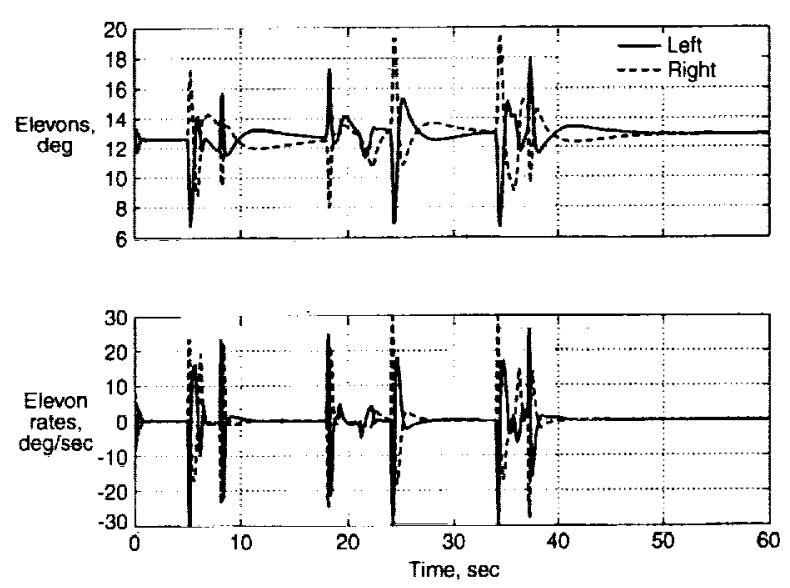

Figure 16. Mach 8 Reverse Aileron Maneuvers. (CG location $=70.3 \%)$

larly during the reverse roll used to complete the maneuver. This technique provided an adequate roll response below Mach 17 as the dynamic pressure increased above $30 \mathrm{psf}$ and performed relatively well to the TAEM interface at Mach 2.5 where the rudder became effective. However, the roll response using the reverse aileron may not be adequate to meet the flight conditions at the TAEM interface and a conventional control strategy may have to be implemented as the flight condition approaches TAEM. Figures 16 and 17 show the elevon and body flap deflections and rates needed to perform the maneuver. The reverse aileron command uses the elevons with some minimal deflection of the body flaps. Pitch control is performed with the same body flap/elevon mixing used in the nominal approach. A comparison of the Mach 8 responses shown in Figures 14 and 18 demonstrates a significant reduction in roll and yaw RCS torque and fuel usage for the proposed technique.
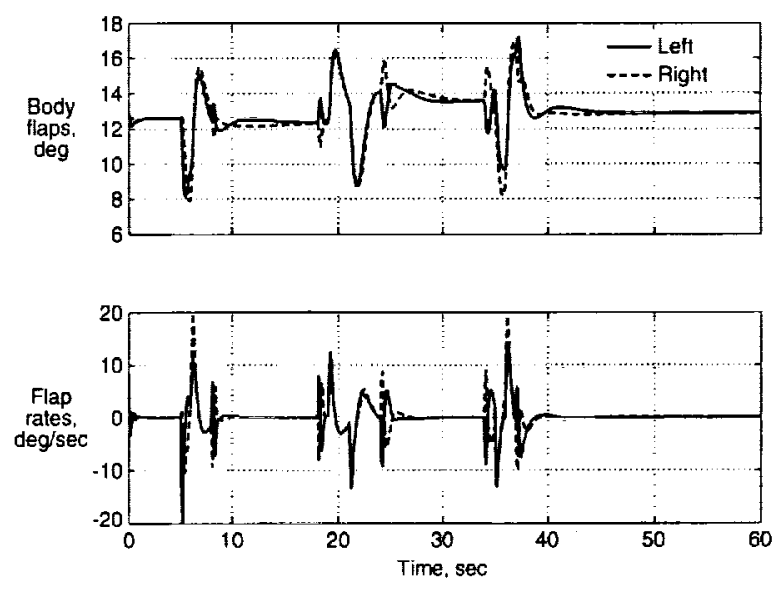

Figure 17. Mach 8 Reverse Aileron Maneuvers (CG location $=70.3 \%)$
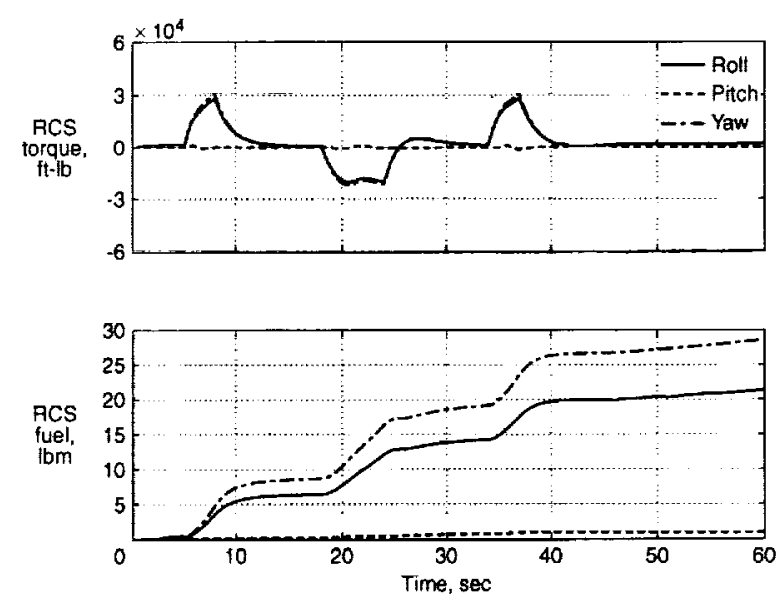

Figure 18. Mach 8 Reverse Aileron Maneuvers . (CG location $=70.3 \%)$

Both control strategies where implemented in the vehicle 6 DOF non-linear simulation with wind gusts applied using the Dryden Wind turbulence model. The gust model parameters where selected to produce winds representative of severe turbulent conditions. ${ }^{8}$ Figures 19-22 show the comparison of the maximum elevon and body flap rates and deflections, RCS torque and fuel usage for the two design strategies across the flight conditions over the range from Mach 25 to 3 . Elevon and body flap commands, saturated at $30 \mathrm{deg} / \mathrm{sec}$ and $20 \mathrm{deg} /$ sec respectively, resulted in maximum deflections within the control surface limits throughout the trajectory. As demonstrated in the comparison of the RCS requirements for the Mach 8 flight condition, the RCS torque and fuel usage were reduced substantially at flight conditions along the trajectory less than Mach 15 for roll and Mach 20 for yaw. The reduction in yaw RCS and increase in roll RCS usage above flight conditions around 


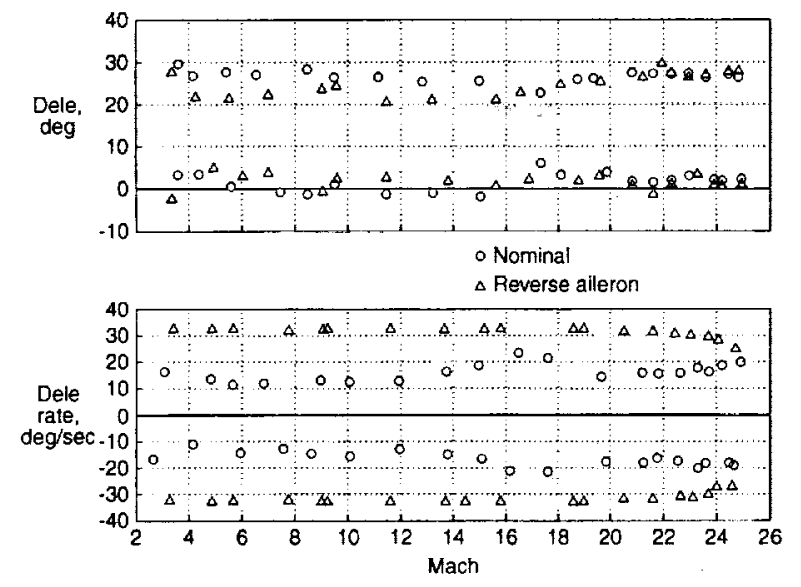

Figure 19. Maximum Elevon Deflections and Rates, Response to Severe Wind Gusts.
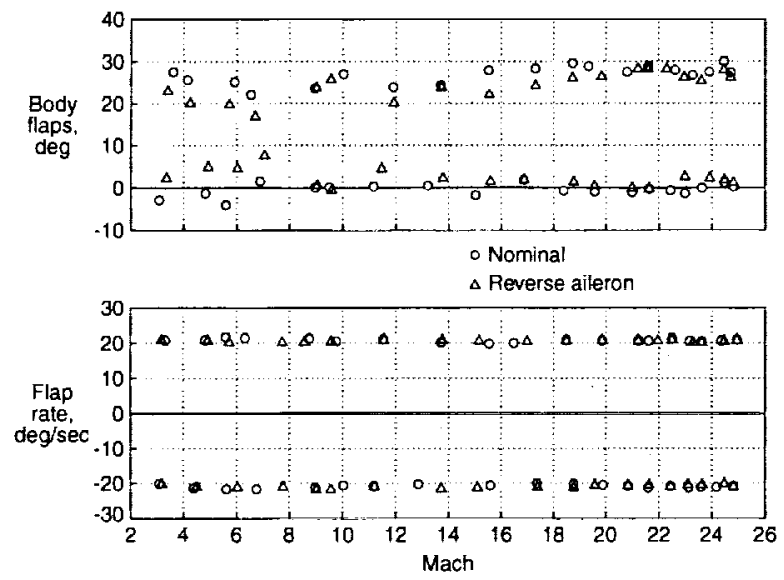

Figure 20. Maximum Body Flap Deflections and Rates, Response to Severe Wind Gusts.

Mach 18-20 resulted from a difference in the body flap/ elevon mixing strategy. These RCS differences did not result from the reverse aileron technique since it was not utilized during this low dynamic pressure region of flight and should not be considered significant when comparing this strategy with the nominal design.

The reverse aileron design demonstrates a potential reduction in yaw and roll RCS authority needed to perform guidance maneuvers in the hypersonic and high supersonic flight regimes. The RCS advantages of this approach, however, are offset somewhat by the disadvantages of the resulting control design. The reverse aileron technique requires a high rate actuation to achieve the initial reverse roll response with induced sideslip. The control design results in a high gain controller with particularly high gains on the sideslip angle. As a consequence the response becomes sensitive to wind dis-
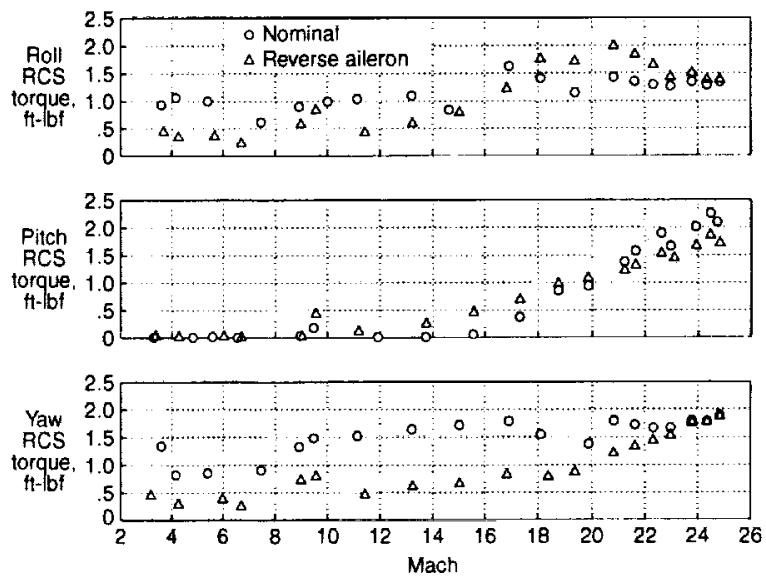

Figure 2I. Maximum RCS Torque, Response to Severe Wind Gusts.
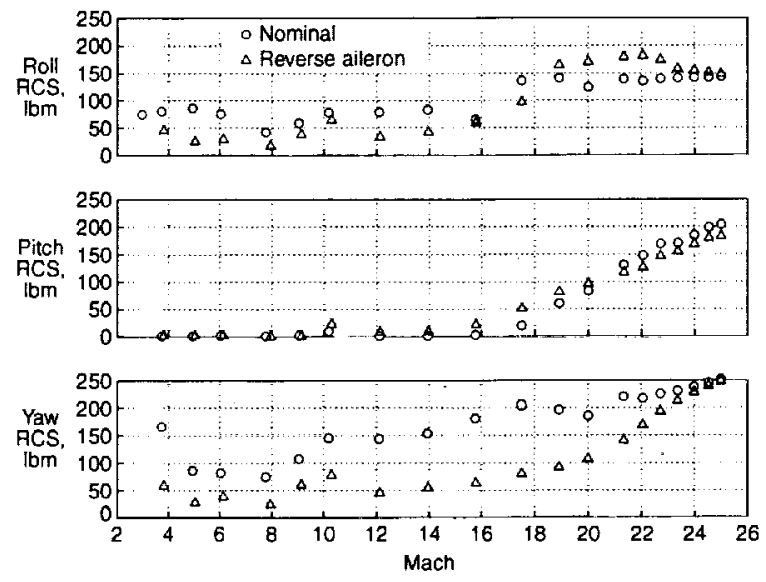

Figure 22. Maximum RCS Fuel, Response to Severe Wind Gusts.

turbances and uncertainties in the aerodynamics. This could impact actuator power requirements as the elevon hinge moments increase with dynamic pressure and result in a control system with reduced stability margins and robustness. The design strategy ultimately chosen for the vehicle will have to trade off these issues to achieve an optimum design.

\section{LANDING APPROACH ANALYSIS}

At flight conditions near the TAEM at Mach 2.5 the angle of attack is reduced to levels that allow the rudder to become effective. Vehicle yaw control is accomplished using the rudder and the RCS is not used for flight below Mach 2. The control response to roll/pitch guidance doublet maneuvers, wind gusts and turbulence from the TAEM interface through subsonic speeds were analyzed using the same non-linear simulation used for the entry 
to TAEM analysis. The resulting control response through transonic speeds using the Dryden gust model parameters was adequate with the elevon and rudder rates limited to $30 \mathrm{deg} / \mathrm{sec}$ and body flap rates limited to 20 $\mathrm{deg} / \mathrm{sec}$. Pitch trim at near Mach 1.5 required body flap deflections of about -10 deg limiting the use of body flaps for control. This flight regime is traversed rapidly during the proposed trajectory and the additional pitch effectiveness of the elevons proved to be adequate to stabilize and control the vehicle. However, pitch controllability through the transonic region will need to be monitored closely to ensure vehicle flyability as the design matures.

A typical subsonic vehicle response at Mach 0.4 to pitch and roll doublet commands and wind gusts are shown in Figures 23-26 for the 70.3\% CG location. The control design demonstrated good roll and angle of at-
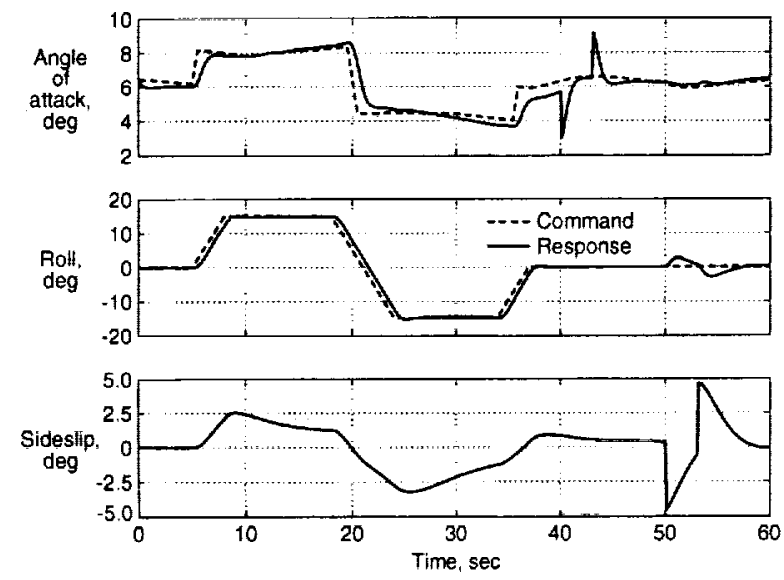

Figure 23. Mach 0.4 Guidance Doublet Maneuvers. $($ CG location $=70.3 \%)$
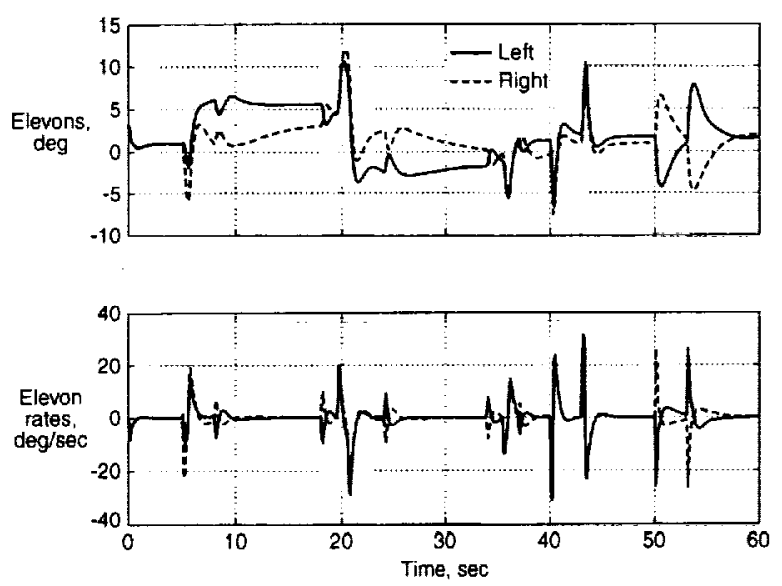

Figure 24. Mach 0.4 Guidance Doublet Maneuvers. $(C G$ location $=70.3 \%)$ tack response with moderate control surface rates and deflections. A discrete vertical wind gust of $15 \mathrm{mph}$ was applied at $40 \mathrm{sec}$ and a lateral wind gust of $25 \mathrm{mph}$ applied at $50 \mathrm{sec}$ to show control response to moderately high wind gusts. Both gusts were implemented as a single square wave pulse of duration $3 \mathrm{sec}$. Good response was achieved demonstrating a well damped control system recovery from an induced 5 deg sideslip and $3 \mathrm{deg}$ angle of attack.

As the vehicle approaches landing at low subsonic speeds the pitch trim deflections were reduced but the longitudinal stability was decreased resulting in higher rates required to stabilize the vehicle. Figures 27-31 show the vehicle response to moderate wind turbulence near landing at speeds less than Mach 0.3. The lateral, longitudinal and vertical winds used for this case are shown in Figure 31 . They include moderate Dryden wind gusts ${ }^{2}$
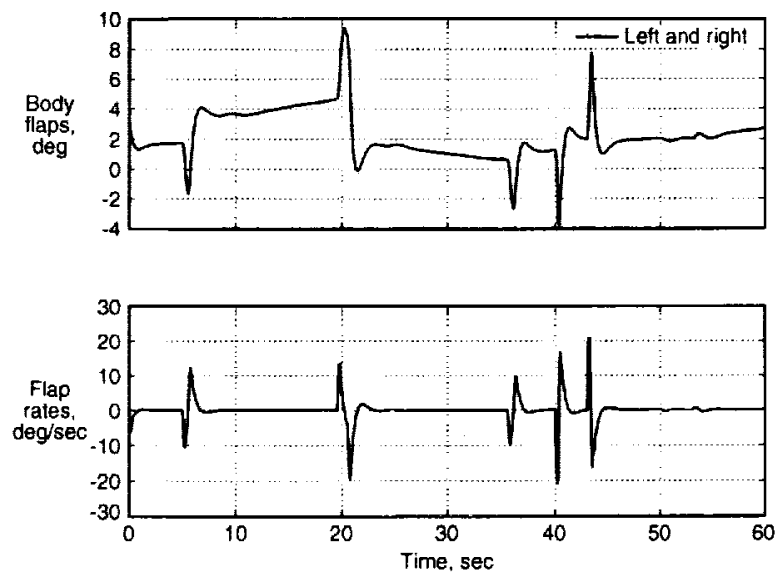

Figure 25. Mach 0.4 Guidance Doublet Maneuvers. $($ CG location $=70.3 \%)$
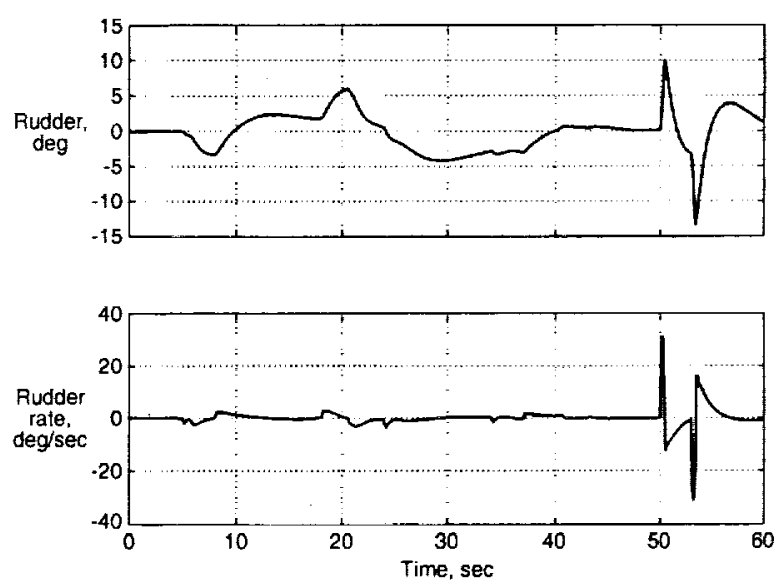

Figure 26. Mach 0.4 Guidance Doublet Maneuvers. $($ CG location $=70.3 \%)$ 
superimposed on a $20 \mathrm{mph}$ crosswind at landing. As the vehicle angle of attack is increased at low subsonic conditions during landing the static margin is decreased resulting in a decrease in pitch stability. The higher gains needed to stabilize the vehicle result in higher surface actuation rates in response to wind gusts. Maintaining the elevon and body flap deflections within the imposed limits required elevon rates of $50 \mathrm{deg} / \mathrm{sec}$ and body flaps rates of $25 \mathrm{deg} / \mathrm{sec}$. The rates will become larger if the vehicle is required to fly in more severe turbulence. The situation is somewhat aggravated by the elevons and body flap deflections required to counter the roll moment induced by the crosswind at landing. Actuation requirements could be reduced by a more forward vehicle CG location or an equivalent adjustment to the vehicle aerodynamic center.
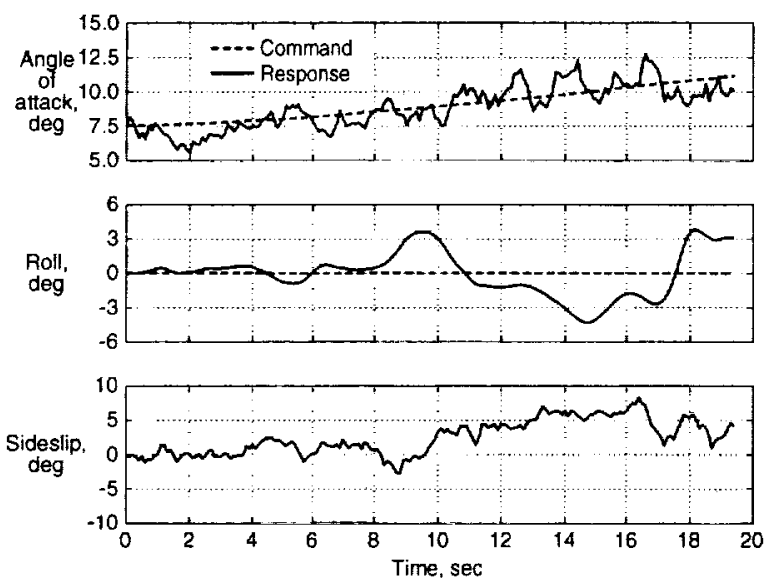

Figure 27. Mach 0.3-0.23 Response to Wind Gusts. (CG location $=70.3 \%)$
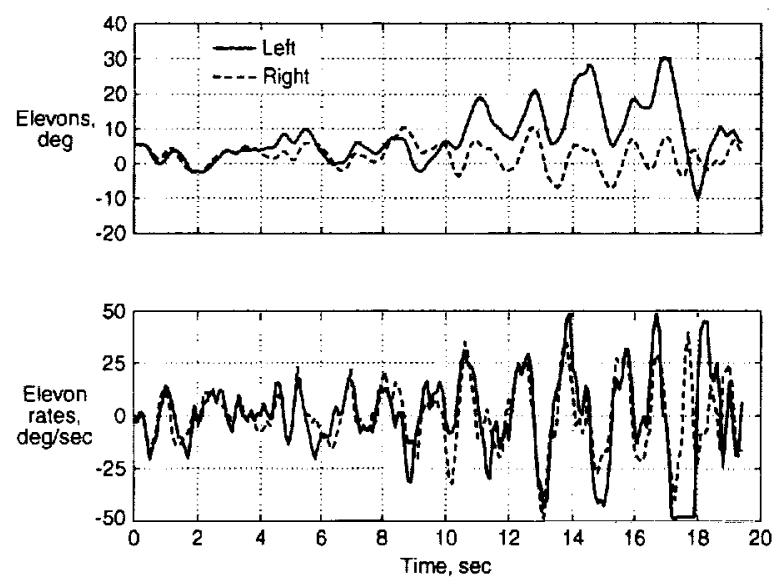

Figure 28. Mach 0.3-0.23 Response to Wind Gusts. (CG location $=70.3 \%)$
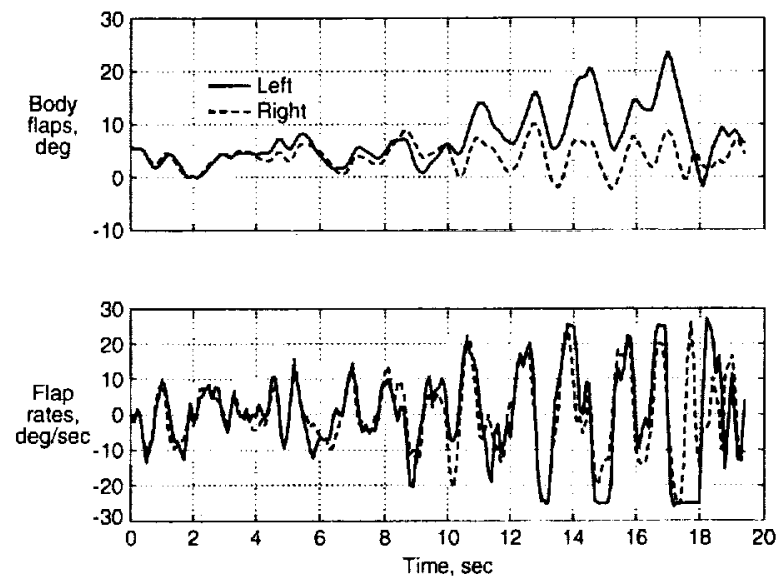

Figure 29. Mach 0.3-0.23 Response to Wind Gusts. (CG location $=70.3 \%)$
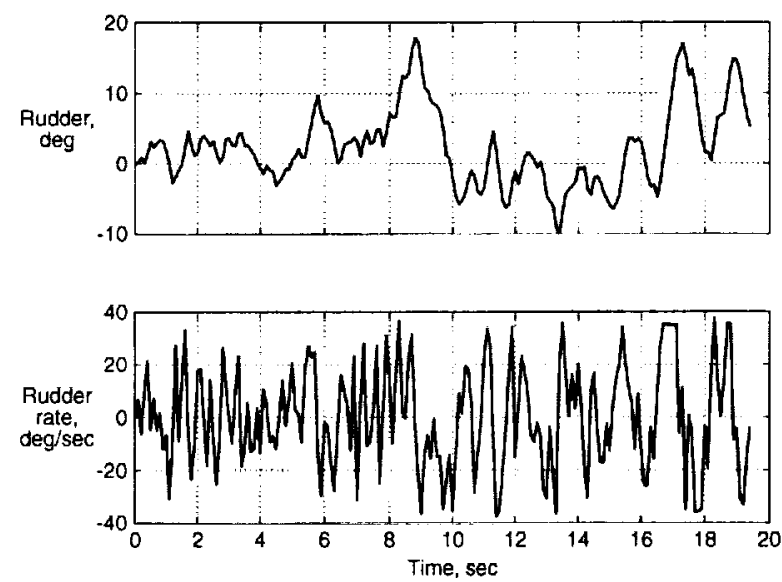

Figure 30. Mach 0.3-0.23 Response to Wind Gusts. $($ CG location $=70.3 \%)$
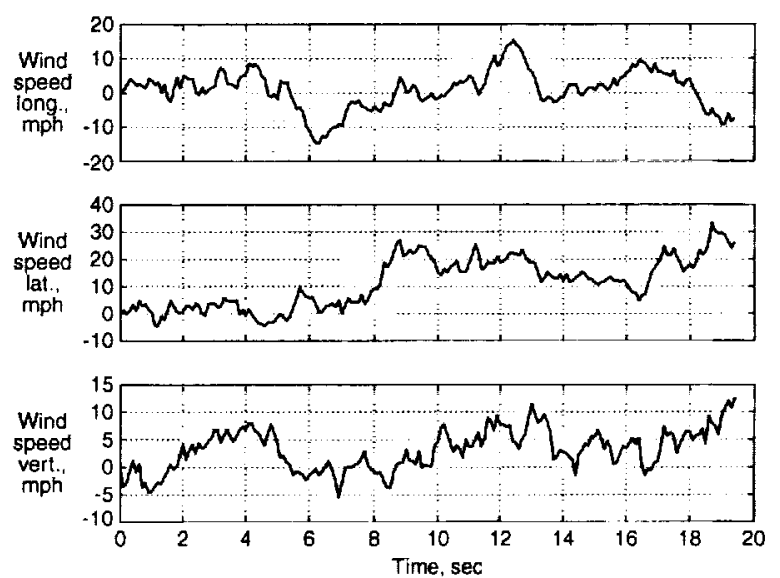

Figure 31. Mach 0.3-0.23 Response to Wind Gust. $(C G$ location $=70.3 \%)$ 


\section{WIND GUST MODEL}

The non-linear simulation includes a model of wind gusts using the Dryden spectrum for wind turbulence. This model is recommended for use to examine vehicle response to wind gusts for horizontally flying vehicles with flight path angles less than $30 \mathrm{deg} .{ }^{8}$ The model output is an approximation of the Von Karman spectrum that can be easily generated in a digital simulation by passing white noise through a shaping filter. The values for the standard derivation and scale of turbulence used in the model were taken from Table 2-79 in reference 2. These parameters determine the magnitude and frequency spectrum of the wind gust model output. These model parameter values are tabulated as a function of altitude and are listed for light, moderate, and severe gust amplitudes along with the probability of encountering these levels. The values for the severe and moderate gusts were used for this analysis to generate the winds referred to as "severe" and "moderate" gusts in the text of this paper.

\section{CONCLUSIONS}

This paper documents work performed at the NASA Langley Rescarch Center to assess the entry flight controllability of a configuration representative of an early VentureStar ${ }^{\mathrm{TM}}$ vehicle concept. The control design was analyzed over the entire Mach range from entry to landing. The analysis discussed the challenges of hypersonic and transonic pitch trimability and subsonic stability, particularly at low subsonic conditions. Surface deflections and rates needed to perform maneuvers and stabilize the vehicle in the presence of wind gusts were determined along the flight conditions of the design trajectory. As the design matures, attention must be given to the CG location, static stability and control surface effectiveness to ensure the combination will provide pitch trim and vehicle flyability over the Mach range. Particular attention to these parameters is recommended for hypersonic and transonic pitch trim and subsonic stability augmentation. Careful consideration will allow closed loop control to be accomplished with moderate demands on surface deflections, actuator rates and power.
The multi-point LQR control design methodology used in this study provided an effective means to access the flyability of the vehicle across the entry trajectory. Adjustment of the LQR weighting matrices produced a useful method for computing the control gains and facilitated the development of alternate control design strategies. The reverse aileron control strategy demonstrated the potential for significant reduction of required RCS control authority for performing bank maneuvers during hypersonic and high supersonic flight.

\section{REFERENCES}

1. Lockwood, M., "Overview of Conceptual Design of Early VentureStarTM Configurations," AIAA Paper 2000-1042, Jan. 2000.

2. Tartabini, P., Lepsch, R., Korte, J., Wurster, K., "A Multidisciplinary Performance Analysis of a LiftingBody Single-Stage-to-Orbit Vehicle," AIAA Paper 20001045, Jan. 2000.

3. Brauer, G. L, Cornick, D. E., and Stevenson, T., "Capabilities and Applications of the Program to Optimize Simulated Trajectories (POST),"NASA CR-2770, February 1977.

4. Weissman, R., "Status of Design Criteria for Predicting Departure Characteristics and a Spin Susceptibility," Journal of Spacecraft and Rockets, Vol 12, No 12, December 1975, pp. 989-993.

5. Grace, A., Laub, A. J., Little, J. N., Thompson, C. M., "Control System Toolbox User's Guide," The Mathworks, Inc., July 1992.

6. Matlab Reference Guide, The Mathworks, 1993.

7. “Using Simulink," The Mathworks, 1996.

8. Johnson, D. L., ed., "Terrestrial Environment (Climatic) Criteria for Use in Aerospace Vehicle Development, 1993 Revision," NASA TM 4511, August 1993. 